\title{
Production of plasma selectively depleted in fibrinogen by affinity chromatography
}

\author{
C F Hirst, K J Stevenson
}

\begin{abstract}
An affinity chromatography column was prepared using a polyclonal anti-fibrinogen antibody bound to Sephacryl S 1000. Normal human plasma was depleted of fibrinogen by passage through this column. The fibrinogen free plasma corrected the prolonged clotting times of plasmas deficient in factors V, VII, VIII and IX. Clottable fibrinogen was recovered from the column. An immunodepleted fibrinogen free plasma could fulfil a useful role in internal and external quality control alone, or in combination with other test materials; it could also be used in research.
\end{abstract}

Plasma deficient in or free of fibrinogen is not readily available commercially. Such material could be of value in internal and external quality control procedures as well as in specialised research investigations. Patients congenitally deficient in fibrinogen are rare and patients with acquired deficiencies of fibrinogen are normally not suitable for plasma donation. Fibrin/fibrinogen degradation products may also be present in the latter. Donations from fibrinogen deficient patients would also require consent so that they could be tested for the possible presence of human immunodeficiency virus (HIV) etc.

The removal of individual coagulation factors from normal plasma using polyclonal ${ }^{1-6}$ and monoclonal ${ }^{7-9}$ antibodies has been described. These have been used as substrate plasmas in the assay of coagulation factors VII ${ }^{6}$ VIII, ${ }^{1-578}$ and IX. $^{9}$ Monoclonal antibodies specific for fibrinogen are available, but because fibrinogen is present in the plasma at a much higher concentration $(\approx 3 \mathrm{~g} / \mathrm{l})$ than factors VII ( $\approx 2 \mathrm{mg} / \mathrm{l})$, VIII $(\approx 0.2 \mathrm{mg} / \mathrm{l})$, or IX $(3-4 \mathrm{mg} / 1)$, a relatively large amount of monoclonal antibody would be required for its removal, which could be prohibitively expensive. For this reason the effectiveness of a relatively inexpensive polyclonal antibody in the removal of fibrinogen from plasma was investigated.

\section{Methods}

for Anticoagulant

Reagents and Control Withington Hospital, Manchester M20 8LR C F Hirst

K J Stevenson

Correspondence to: Dr Stevenson

Accepted for publication

6 December 1990

\section{COLUMN PREPARATION}

Sephacryl S 1000 (10 ml) obtained from Pharmacia Ltd was activated by periodate oxidation according to the method of Hornsey et $a l .{ }^{10} \mathrm{~A}$ purified immunoglobulin fraction of rabbit antihuman fibrinogen antiserum with a protein concentration of $7 \cdot 2 \mathrm{~g} / 1$ was obtained from Dako Ltd. Coupling of antibody to the activated gel was also as described by Hornsey et al. $^{10}$ Ten millilitres of activated Sephacryl, $10 \mathrm{ml}$ of anti-fibrinogen antibody, and $10 \mathrm{ml}$ $1 \mathrm{M} \mathrm{Na} \mathrm{CO}_{3}$ buffer ( $\mathrm{pH} 9.0$ ) were mixed and $10 \mathrm{mg}$ ascorbic acid added. The mixture was adjusted to $\mathrm{pH} 9.0$ and mixed on a roller mixer overnight at room temperature. Blocking of non-coupled groups on the gel was achieved by adding $10 \mathrm{ml}$ of $0.1 \mathrm{M}$ ethanolamine at $\mathrm{pH} 9.0$ and $10 \mathrm{mg}$ of ascorbic acid. Roller mixing was continued for three hours at room temperature. The gel was allowed to settle and the supernatant removed by use of a glass sinter tube connected to a vacuum pump. The gel was washed in $20 \mathrm{ml}$ of distilled water and sucked dry. Washing was continued with $20 \mathrm{ml}$ cycles of $0 \cdot 1 \mathrm{M}$ sodium

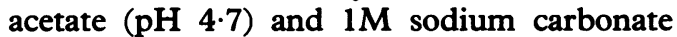
(pH 9.0) and again sucked dry. Finally the gel was washed with $20 \mathrm{ml}$ of distilled water, sucked dry, and suspended in $10 \mathrm{ml}$ of equilibration buffer (50 $\mathrm{mM}$ TRIS $0.1 \%$ sodium azide ( $\mathrm{pH} 7 \cdot 3$ )).

The gel was packed into a siliconed $1.6 \times 20 \mathrm{~cm}$ chromatography column fitted with end adaptors (Pharmacia) and equilibrated with five column volumes of equilibration buffer at a flow rate of $10 \mathrm{ml} /$ hour. Protein in the column effluent was monitored at $254 \mathrm{~nm}$ on a Gilson model III UV detector connected to a Gilson NI chart recorder (Anachem Ltd)

\section{PLASMA PREPARATION}

A whole blood donation, negative for hepatitis B surface antigen and HIV antibodies, was centrifuged at $5 \times 10^{3} \times g$ for 15 minutes at $4^{\circ} \mathrm{C}$. The plasma was removed and centrifuged at $23 \times 10^{3} \times g$ for 30 minutes. The clear plasma was removed from below the lipid rich layer and filtered through a Millipore Sterivex 0.22 $\mu \mathrm{m}$ filter. The filtered plasma was stored frozen at $-80^{\circ} \mathrm{C}$ before use.

FIBRINOGEN DEPLETION AND ELUTION

Twenty millilitres of filtered plasma were thawed and warmed to $20^{\circ} \mathrm{C}$. A $1 \mathrm{ml}$ aliquot was retained for subsequent tests and $15 \mathrm{mI}$ was applied to the column at a flow rate of $10 \mathrm{ml} /$ hour. Plasma was collected in $1 \mathrm{ml}$ aliquots following the detection of protein in the column effluent. Because of dilution with equilibration buffer before and after the plasma sample, a total of 20 aliquots were collected. The column was re-equilibrated 


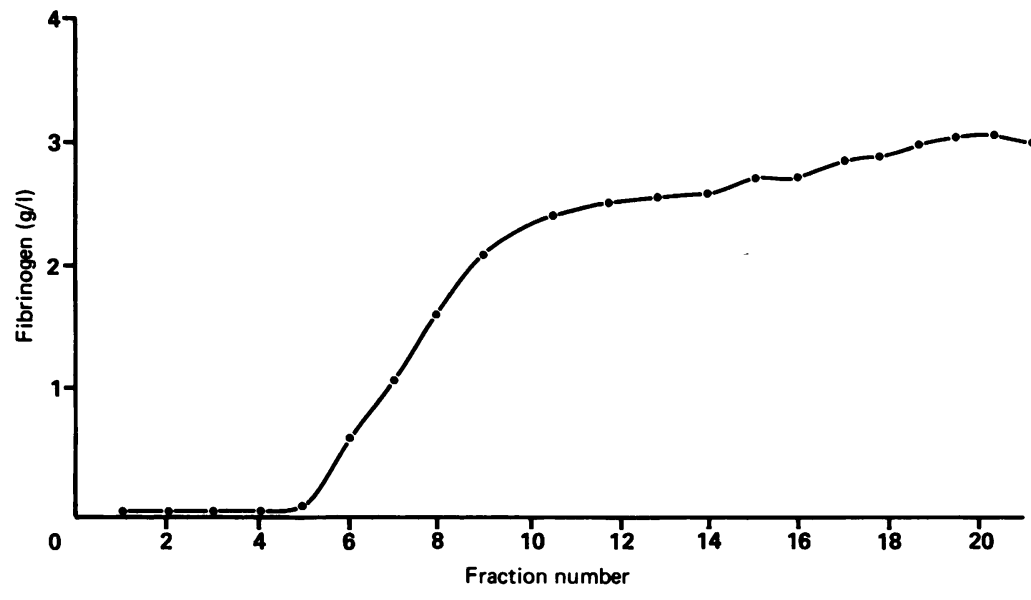

Figure 1 Fibrinogen concentration of $201 \mathrm{ml}$ fractions of plasma from an antifibrinogen affinity chromatography column. The column is seen to remove the fibrinogen from $4 \mathrm{ml}$ of plasma and is subsequently saturated.

with $20 \mathrm{ml}$ of equilibration buffer and bound fibrinogen was removed with elution buffer ( $7 \mathrm{M}$ urea, $\mathrm{pH} \mathrm{7 \cdot 0)}$. The eluted fibrinogen was collected into a single $3 \mathrm{ml}$ volume.

TESTS ON THE FILTERED PLASMAS

The filtered plasma was tested for fibrinogen concentration according to the method of Clauss. ${ }^{11}$ A prothrombin time (PT) estimation

Figure 2 Densitometric scans of pre-column plasma $(A)$ fraction 2 $(B)$ and fraction $15(C)$. The fibrinogen peak is evident in scans $A$ and $C$ (arrowed) but is absent from scan $B$. and an activated partial thromboplastin time (APTT) were also performed. The PT was performed with Manchester Reagent (Manchester Thrombosis Research Foundation) and the APTT with Manchester APTT Reagent (United Kingdom Reference Laboratory). Protein electrophoresis was carried out using a Gelman protein electrophoresis system with densitometric scanning of separated fractions.

\section{TESTS ON THE EFFLUENT PLASMA}

The effluent plasma fractions were tested for fibrinogen concentration. Protein electrophoresis of fractions 2,6 , and 15 was carried out as described above. Those fractions containing no detectable fibrinogen were pooled.

Plasma deficient in factors V, VII, VIII and IX were obtained from Immuno Ltd and mixed in equal volumes with the fibrinogen free plasma. A PT/APTT (as appropriate) was performed on both the deficient plasma and the mixtures.

\section{TESTS ON THE ELUTED FIBRINOGEN}

Urea was removed from the recovered fibrinogen by dialysis in an. Amicon Model 12 stirred cell concentrater. After two washes in distilled water the fibrinogen was concentrated to $2 \mathrm{ml}$ and assayed in the same way as the plasma fractions.
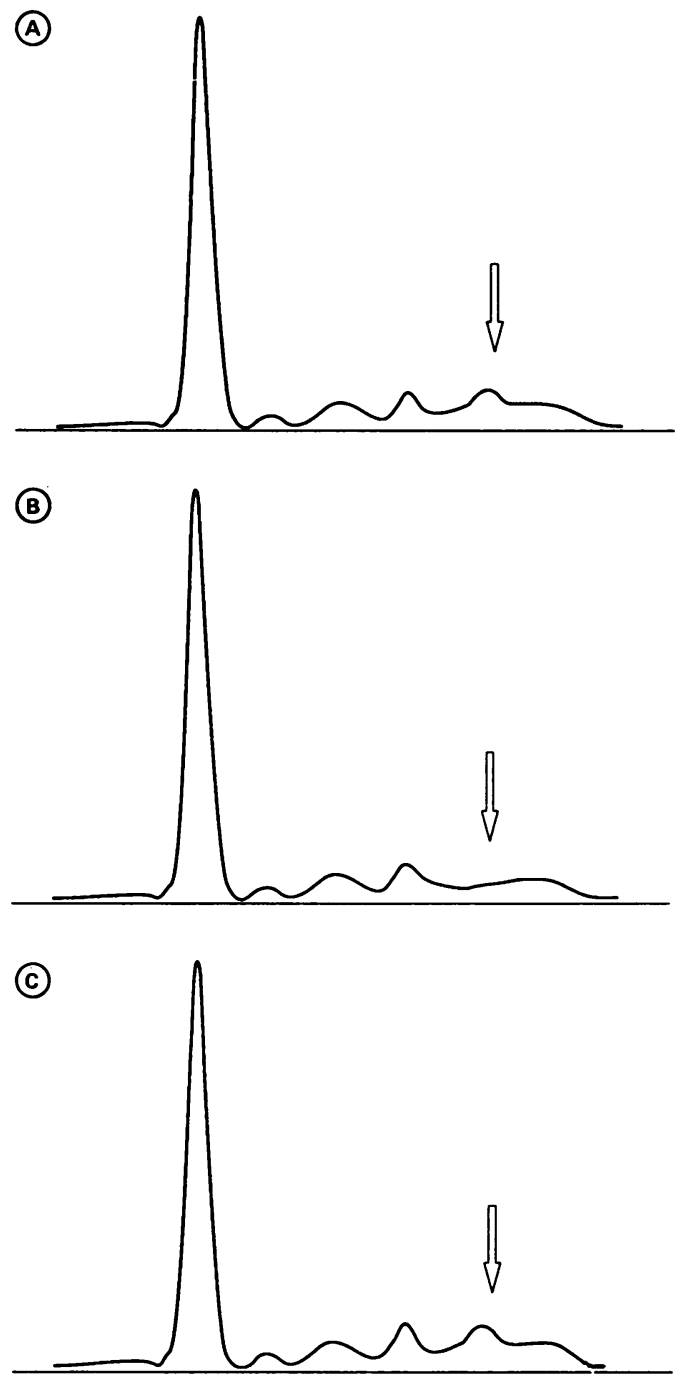

\section{Results}

The fibrinogen concentration of the filtered plasma was $3.6 \mathrm{~g} / 1$ (normal range $2 \cdot 0-4.0 \mathrm{~g} / \mathrm{l}$ ). The PT and APTT times of the filtered plasma were 16.5 and $48 \cdot 0$, respectively (normal ranges $13 \cdot 7-17 \cdot 7$ and $36 \cdot 0-48 \cdot 0$ ).

The fibrinogen concentrations of the 20 effluent plasma fractions are plotted against fraction number (fig 1). Fibrogen was not detectable in the first four $1 \mathrm{ml}$ fractions.

Densitometric scans of protein electrophoresis of the pre-column plasma and fractions 2,6 , and 15 showed that a band between the $\beta$ and $\gamma$ regions, presumed to be fibrinogen, is absent from fraction 2 , is beginning to reappear in fraction 6 , and is fully present in fraction 15. Scans of the pre-column plasma and fractions 2 and 15 are shown in fig 2 .

The PT and APTT of the deficient plasma and the mixtures are shown in the table. The prolonged clotting times of plasmas deficient in factors V, VII, VIII and IX are all substantially reduced indicating correction by the fibrinogen depleted plasma.

The desalted fibrinogen had a volume of $2.0 \mathrm{ml}$ and on the addition of thrombin in the Clauss fibrinogen assay a weak clot was produced at a dilution and time which indicated a fibrinogen concentration of about $0 \cdot 1 \mathrm{~g} / 1$.

\section{Discussion}

The method of Hornsey et $a l^{10}$ has been shown to be a simple and reliable technique for the activation of Sephacryl S 1000 and the coupling to this of the immunoglobulin fraction of a 
Correction of prolonged clotting times of factor deficient plasmas by addition of fibrinogen free plasmo

\begin{tabular}{|c|c|c|}
\hline $\begin{array}{l}\text { Factor deficient } \\
\text { plasma }\end{array}$ & & \\
\hline \multirow[t]{2}{*}{$\begin{array}{l}\text { V } \\
\text { VII }\end{array}$} & $\begin{array}{l}\text { Prothrombin } \\
\text { time (seconds) } \\
102 \cdot 2 \\
85 \cdot 0\end{array}$ & $\begin{array}{l}\text { Prothrombin time of an equal volume mixture of deficient } \\
\text { plasma and fibrinogen deficient plasma (seconds) } \\
20 \cdot 0 \\
21 \cdot 1\end{array}$ \\
\hline & $A P T T$ (seconds) & $\begin{array}{l}\text { APTT of an equal volume mixture of deficient plasmas } \\
\text { and fibrinogen deficient plasma (seconds) }\end{array}$ \\
\hline $\begin{array}{l}\text { VIII } \\
\text { IX }\end{array}$ & $\begin{array}{l}207 \cdot 0 \\
128 \cdot 5\end{array}$ & $\begin{array}{l}62 \cdot 0 \\
61 \cdot 5\end{array}$ \\
\hline
\end{tabular}

polyclonal anti-fibrinogen antibody. Ten millilitres of this antibody preparation containing $72 \mathrm{mg}$ of protein can remove fibrinogen from $4 \mathrm{ml}$ of suitably prepared normal human plasma. The high speed centrifugation step separated the plasma into three layers. The lower layer comprised particulate debris, the middle layer clear plasma, and the upper layer opaque lipids. Only the clear layer was selected for depletion after further filtration. Column blocking was prevented by these steps. The fibrinogen depleted plasma was shown to contain adequate amounts of factors V, VII, VIII and IX to restore the clotting defects of severe deficiencies of these factors. Such a plasma could, on admixture with a normal plasma, provide a range of low fibrinogen plasmas for use in internal and external quality control. The fibrinogen eluted from the column was clottable, but the quality of the clot was friable. It is almost certainly the case that the Clauss assay value obtained on the eluted desalted fibrinogen is not indicative of the true concentration of fibrinogen removed. This may be due to partial loss or denaturation of the fibrinogen either by the elution buffer or by changing ionic conditions during the desalting process. The elution buffer was designed to remove bound proteins from the column, leaving it ready for reuse. It was not designed to elute functional fibrinogen. A more suitable elution buffer may be devised for this purpose. Fibrinogen so obtained might nevertheless be used to sup- plement normal plasma fibrinogen concentrations to provide a high fibrinogen plasma. Larger volumes of plasma could be processed by use of a larger column or by reuse of the smaller column.

A fibrinogen free plasma also provides a laboratory reagent with new properties. An activation process, which with normal plasma produces a fibrin clot, would with this plasma only produce thrombin. If a fibrinogen free plasma were to be further depleted of another coagulation factor it could be used as a substrate plasma for a thrombin sensitive, chromogenic substrate-based specific coagulation factor assay.

We are deeply indebted to Drs CV Prowse and D S Pepper of the Scottish National Blood Transfusion Service, Edinburgh, for providing the method for the coupling of antibody to solid phase providing the method for the coupling of antibody to solid phase
used in this report and for their advice on the technique and its used in this
application.

1 Exner T, Rickard KA, Speers S. Factor VIII deficient plasma for laboratory tests prepared from normal plasma and a human antibody. Haemostasis 1977;6:157-62.

2 Furlan M, Felix R, Beck EA. Preparation of factor VIII deficient plasma by immunoadsorption. Vox Sang 1979; 36:342-6.

3 Tuddenham EG, Trabold NC, Collins JA, Hoyer LW. The properties of factor VIII coagulant activity prepared by immunoadsorbent chromatography. J Lab Clin Med 1979; 93:40-53.

4 Ofusu F, Cassidy K, Blajchman MA, Hirsh J. Immunodepletion of human plasma factor VIII. Blood 1980;56: 604-7.

5 Tran TH, Duckert F. Preparation of factor VIII free plasma by immunoaffinity chromatography on insolubilized antibodies against factor VIII related antigen. Haemostasis 1983;13:73-7.

6 Osamu T, Funahashi S, Yoshioka K. Preparation of factor VII-depleted plasma by immunoaffinity chromatography of insolubilised anti-factor VII. Med Lab Sci 1986; 43:215-19.

7 Takase T, Rotblat F, Goodall AH, et al. Production of factor VIII deficient plasma by immunodepletion using three monoclonal antibodies. Br J Haematol 1987;66:497-502.

8 monoclonal antibodies. Br J Haematol 1987;66:497-502. VIII deficient plasma: preparation using monoclonal antibodies and its use in one stage coagulation assays. $J$ Clin Pathol 1988;41:562-7.

9 Bessop H, Prowse CV, James K. Human coagulation factor IX: direct depletion and recovery from plasma using immobilised monoclonal antibody. Med Lab Sci 1988; 45:261-5.

10 Hornsey VS, Prowse CV, Pepper DS. Reductive amination for solid phase coupling of protein. A practical alternative to cyanogen bromide. J Immunol Methods 1986;93:83-8.

11 Clauss VA Gerinnungsphysiologische schnellmethod zur bestimung des fibrogens. Act Haematol 1957;17:237-46. 